\title{
Education policy and the socio-spatiality of school reform - learning support spaces as perceived by students in the context of the new middle school policy in Austria
}

\section{Mariella Knapp, Michaela Kilian, Tamara Katschnig}

\begin{abstract}
Education policies are socio-spatially sensitive and, depending on the local situation, can be interpreted and understood differently. The concept of perceived learning support spaces (e.g. student cooperation, student-teacher relationships) refers to an understanding that students' school experiences are situated within the school. Using the example of the introduction of a new type of school, the new middle school (NMS), in Austria, and based on the longitudinal data of a national evaluation project (NOESIS), this article aims to clarify the extent to which, and how, student learning support spaces are perceived as local social conditions inside and outside school, and how this can explain changes in students' educational aspirations, which was the objective of the NMS reform. In this sense, the reform policy of introducing the new middle school is examined from the perspective of the students themselves. The results from the panel analyses demonstrate that the perceived learning support spaces are highly relevant in explaining students' aspirations.
\end{abstract}

Keywords: educational policy, school reform, space, geography of education, educational aspirations 


\section{Introduction}

This paper draws on the conception of learning support spaces understood here as a construct for researching the relationship between education policies and their spatial significance. Based on Löw's (2001) concept of space as a relational arrangement of social goods and people at a specific place, learning support spaces in schools are viewed as a conglomerate of material resources and social relationships aiming to offer possibilities for students' further educational pathways. It is assumed that the impact of spaces or contexts becomes obvious only through individuals' perceptions of them. In this sense, students' experiences in class and at school are seen as manifestations of learning support spaces. Using the example of the new middle school, a centrally based policy reform in Austria, we want to investigate the extent to which the learning support spaces that were established and restructured through this reform explain the policy's main objective of increasing and maintaining high student aspirations. In the first step we give a deeper explanation of our concept of learning support spaces and why students' experiences of them (perceived learning support spaces) seem to be a relevant category for studying school reforms. Next, we point to the relevance of adopting a spatial perspective in education policy and present the cornerstones of the new middle school reform. Then we present the database and the results of the longitudinal study. Researching the perceived learning support spaces in a reform context seems to be an interesting way of gaining a better understanding of the relationship between policy, reform and the local.

\section{Learning Support Spaces and the Geography of Student Experiences}

As theories and methods of the social and cultural sciences opened up in geography, there was an accompanying shift away from space as process and towards space in process (Gulson \& Symes, 2007), while a growing interest in students as key social and spatial actors has been observed since the 2000s (Taylor, 2009; Freytag, Jahnke \& Kramer, 2015). The establishment of a "Geography of Children" as a sub-discipline (Holloway, Hubbar, Jöns \& Pimlott-Wilson, 2010) highlights the importance attributed to young people. Based on research into how children conceptualize and experience space, the goal is to bring to the fore the subjects of these processes of spatial appropriation, such as the students who are involved in learning and teaching processes (Holloway et al., 2010). In the sense of a "geography of education and learning", they "consider the importance of spatiality in the production, 
consumption and implications of formal education systems from pre-school to tertiary education and informal learning environments in homes, neighbourhoods, community organizations and workspaces" (Holloway \& Jöns, 2012, p. 482). A correspondingly comparable perspective is only slowly being established in the German-speaking world as the "Social Geography of Children" (Werlen \& Reutlinger, 2019) and as an interdisciplinary construct between social geography, sociological research on students, social work and education science. While education science is undergoing a "spatial turn", in geography, the counterpart of the focus on the lifeworld of students can be found in a "childhood turn" (Taylor, 2009). The making of sociospatial identities and spaces is now coming to the fore. Although an increasing number of studies conducted within the geography of education and learning concern the psychogeographies or geographies of children's emotions inside and outside school (e.g. Kustatscher, 2017; Brown, 2011), little attention is paid to the perspective of the child as a learner (Taylor, 2009). This perspective is also of interest when looking at school reforms, as most innovations in the school system focus on students and their development. Therefore, it is relevant to see if and how these innovations reach students and become obvious in their spatial representations in terms of their daily experiences of school life. Nevertheless, education and schools are also increasingly seen as important features of social geography generally, and in terms of community and neighbourhood (Collins \& Coleman, 2008; Gulson $\&$ Symes, 2007). Bearing in mind that students spend nearly most of their time in school, schools become highly significant institutional places with which children engage (Cudworth, 2015). In the subsequent analyses in this article, reforms and their interplay with spatial aspects and conditions are at the centre; school can be seen as a place of learning that creates conditions that in turn enable or hinder the development of the student (learning support spaces).

In accordance with the sociological theory of Löw (2001), space is seen as a relational arrangement of social goods and persons at given places. Drawing on this space approach we conceptualize learning support spaces as relational arrangements of (physical) materials in classes and schools, but also of teachers and classmates and aimed at supporting student's education and learning. The arrangement of learning support spaces also implies social relationships between students, and between students and teachers; but it can also follow through with instructional or socio-emotional assistance. Nevertheless, learning support spaces can only lead to actions through perception by the actors. For example, students will view their school as supportive if they perceive and experience their teachers giving 
them good instructions or tips on how to learn. In this sense, we zoom in on the perceived learning support spaces as external images of the social relationships and social goods that result in the personal perceptions of them. Löw (2001) describes these perceptions as "atmospheres" that make people feel good or bad in the specific spatial arrangement at school. "Atmospheres" result from the perception of interactions between people and/or together with external effects of the arrangements of social goods. They are bounded on the constitution of spaces. Conversely, atmospheres also affect how these spaces are constituted. The perceived learning support spaces are interpreted as spaces experienced inside and outside school that are produced by social relationships and foster or restrict students' perceptions of possible modes of action. For instance, if the student experience is of a bad atmosphere in their classes and not much support from their teachers, it seems unlikely that they will enjoy being at that school for a long time. Learning support spaces are strongly relevant to students achieving the learning goals set by their schools, and are a good parameter of the reform processes in schools. We discuss learning support spaces in an attempt to extend the classical understanding of a geography of education and combine it with the geography of children, youth and family approach, so support systems in families and schools can be perceived as socio-spatial practices. Focusing on students' experiences of learning and their perceptions of learning support spaces within the new middle school, we share an "inward looking" perspective in geographical research on education (Hanson Thiem, 2009). Concerning the scale of a geography of education (Taylor, 2009), we situate our study on a micro scale since the research focuses on the students' perspective as learners and the school as a "space" for learning and support. This also indicates that learning and teaching are not only understood from within the school, but from outside as well - in the family, the local and the community context - and in the different policy contexts in which the space is embedded. Our approach is to take the new middle school reform and see how learning is perceived as changing across different grades in existing support systems.

Experiences of learning support spaces can lead to different opportunities, desire for action and future plans, such as the wish to attend university or to finish school. These future plans or educational aspirations are mostly influenced by earlier learning experiences within and outside school. As the new middle school reform was designed to tackle students' educational aspirations and mobilization, we wanted to see if students' aspirations changed during new middle school and if so, which learning spaces could be related to this. Holloway and Pimlott-Wilson (2011) underline the 
importance of studying aspirations within the school context, as well as the need to undertake research in a manner that links schools to their different contexts. The educational aspirations of students and young people have always been a key theme in educational geography, often in the context of school provision and parental school choice. Student achievement and educational aspirations have also become the subject of most educational policy interventions worldwide (Holloway, Brown \& Pimlott-Wilson, 2011). Nevertheless, how they evolve can be understood in socio-ecological terms (Eirmbter, 1982) like many spheres of life (family learning support spaces, school learning support spaces) contribute to their growth. Our aim is not only to see if students adapt to these mostly "middle-class" conceptualized aspirations, but to determine if they change over time at school and how they are embedded in the broader spatial context within which learning support spaces are perceived.

\section{Education Policy, School Reform, and Space}

This conceptualization of learning support spaces is an attempt at better understanding the relationship between education policies and spaces. Policy research and education policies, mostly lack a sense of "space" and "place" because sense of locality is neglected in the analysis of policy realization (Ball, 2006). The policy space is often seen as a container filled with subjects and interactions that remain stable (Gulson, 2008). Based on the assumption of equal school conditions ("all schools are equal"), the derived policies are usually thought of without their spatial reference; yet at each level of implementation we can find adaptation to the spatial conditions. This is especially the case in centralized reforms. The "grammar of schooling" (Tyack \& Tobin, 1994) usually works against this; not only do reforms change schools, but schools change reforms. Such adaptation processes can be described using the term "policy enactment" (Braun et al., 2011). Depending on the social and spatial conditions, policies can have different effects. Fink (2000) claims that centralized reforms affect schools differently depending on where they are located, and how schools influence one another.

The local success of new comprehensive school reforms concerning structural and pedagogical innovations depends on the local reputation of the school, the attitudes of the teachers, the school culture and how this relates to what other schools have to offer (Drope \& Jurczok, 2013; Strohmaier \& Immerfall, 2016; Knapp \& Kilian, 2019). School policy thus directly affects the socio-spatial differentiation of cities and rural areas by influencing spatial action and intervening in existing socio-spatial structures (Freytag \& 
Jahnke, 2015). Several studies attempting to show the connections between reform policy, schools and their environment explain these by using different terms. Buendia, Ares, Juarez \& Peercy (2004) observed that the production of a city-wide East-Side and West-Side space in local learning knowledge was strongly related to the institutional technologies and practices used in the schools. The socially constructed differentiation between the areas existed as a spatial code, which was spread through communication and information processes in the neighbourhoods and transferred to the schools. It guided teachers' talk as locally existing knowledge about how to think and act towards students, parents and families. This local knowledge also resisted change through literacy reform processes, and instead of breaking up this differentiation, seemed to strengthen it. Research also suggests that, through experiences in schools, local knowledge is inscribed into the meaning students make and informs their actions (Yoon, 2016; Gustafson, 2011).

Another example of this kind can be found in Norway's learning regions project. The researchers investigated why students in a particular region obtained high test scores despite the mean socio-economic composition of the inhabitant population in their region which is assumed to indicate otherwise (Midtsunstad \& Langfeldt, 2018). They found that the constitutional mindsets and the connected local expectation structure in the region seemed to be important for students' learning, as it shaped the culture of these schools and had an influence on communication during the lessons. All of these examples show that just focusing on a neighbourhood's characteristics can be too limited a way of looking at the spatial influences on student development. It is not just the neighbourhood effects usually discussed (e.g. Zangger, 2015), but also about how people construct and make sense of their space. At this point student perceptions of learning support spaces might be a useful concept for capturing local experience of reforms at the school level and to better understand how spaces are becoming significant within schools.

In this sense, the concept of geography or space is always assumed as a social understanding. Space is simultaneously a social and a physical phenomenon, a means and a result of human interaction (Hargreaves, 2002). In the context of reform processes, spatial representations in particular can also be understood as images, myths or metaphors that are relevant to the person's construction of meaning and reality. In school reform processes, it is necessary to both redefine these "mythical spaces" of the "imaginary geographies of schools" and redesign the physical component as a distanced and isolated space, as school improvement is generated by the introduction of new myths (Hargreaves, 2002). 


\section{New Middle School Policies in Austria}

Insofar as the new middle school reforms in Austria are concerned, myths were created around the poor results of the PISA 2006 test, and the promise that the new middle school would:

- be a school for all children,

- reduce marginalization,

- promote student talent and expand support systems for low achievers,

- but also improve and maintain high educational aspirations in students,

- boost the reputation of local secondary schools,

- and counteract the growing popularity of academic secondary schools.

The new middle school was introduced as a new type of school in the restructuring of Secondary I in Austria (5th to 8th grade) that would replace the old lower secondary school (Hauptschule). Besides the new middle schools, academic secondary schools (AHS) still exist that provide a direct route into university for academic achievers. The academic secondary schools are becoming increasingly attractive to parents and children so the restructuring of Secondary I through the implementation of the new middle school as an innovative school type was designed to make the general school track become more attractive. In response to the poor PISA results in 2006, the introduction of the new middle school was intended to improve the lower secondary track and raise students' educational aspirations. The idea was to achieve these goals through instructional and pedagogical innovations. In 2008 the reform was launched as a voluntary school trial with secondary schools deciding if they wanted to become new middle schools. This school trial gave the schools more autonomy as they were able to reorganize and restructure their pedagogical settings and plan a new local school profile. In this sense the initial reform involved a local perspective on school improvement. Each federal state in Austria emphasised different aspects, and the schools also had this option, which gave them space to adapt, enact policy and change according to their perceptions of their local situation and environment. Spatial and geographical aspects were not included in the reform policy, but when implementing the reform schools could incorporate them at the school level. In this context, the reform started with a development mythos and the chance to connect at the same level as the academic secondary schools. Nevertheless, in 2012 the Ministry of Education decided to cancel the trial and to launch the new middle school through a comprehensive and standardized school reform throughout Austria. All lower secondary schools had to become new middle schools and implement the following innovations: 
- team-teaching (in the main subjects),

- student-parent-teacher conferences (led by students),

- a change in the grading system (with a new differentiation between general and advanced education),

- discontinuing course-by-course streaming according to student achievement level but allowing the creation of flexible student groups in line with the teaching purpose,

- further instructional innovations were to be integrated within the schools through a special teacher-leader (Lerndesigner), with extra funding and a reduced teaching workload.

Previous autonomy in structuring and organizing teaching was now limited as all new middle schools had the same reform profile that no longer left room to reflect local conditions. At this point the reform policy did not recognize that schools were embedded within the broader community, a locally underpinning social structure. Schools and school culture were envisaged more as citadels (Manchester \& Bragg, 2013), as controllable and manageable units, receptive only to the purposes of educational management and impermeable to their immediate surroundings. In the policy reform the location of the school was conceptualized as an absolute space or "container", with school districts and school zones, but was blind to the possibility that local traditions, attitudes, rules, expectations and the significance of different places might be important for teaching and learning within the school, and student aspirations, as well as ideas about what is and is not acceptable. As the reform took on a more comprehensive form, the surrounding mythos also changed since the new middle school seemed increasingly under pressure to legitimize the reform and explain the benefits to parents and students. The subsequent politics of blaming new middle schools for poor test results in standardized testing against the high expectations of the reform (BIFIE, 2015) and the media coverage ran counter to the attempts to establish a school improvement mythos. Depending on the local knowledge of the schools and the spatial codes underpinned by the communication structure of the school environment some schools fared worse than others in establishing, maintaining and legitimizing the mythos of being a new middle school.

Using empirical data from a national evaluation study (NOESIS) and taking the Austrian reform of the implementation of the new middle school as an example, we want to show why space and geography are relevant for questions of education, school reform and school improvement. Using "learning support spaces" as a construct to describe students' learning con- 
ditions that were enabled by the new middle school reform may help us to better understand the relationship between education policy and the spatial conditions of the implementation in schools. Learning support spaces are conceptualized as opportunities for students to flourish and extend their future goals, but also to fulfil their goals at a specific moment and in a particular place or framework. They are established through social interaction and arrangements between materials and/or between people. In this sense, learning support spaces can be seen as relational spaces and social constructs as they always have to be constituted anew. School reforms such as the introduction of the new middle school focused on the established learning support spaces in schools which were intended to give schools the opportunity to restructure and reorganize themselves positively through pedagogical innovations; this would ultimately manifest itself in students' school experiences and in their aspirations for a high education career. As students' aspirations were paramount in this reform, we take them as our reference point for explaining how and to what extent they are related to the perceived learning support spaces.

Therefore, the study is guided by the following research question: "To what extent can aspirations, as the objective of the new middle school reform, be explained by the learning support spaces perceived by students?". The reform evaluation (NOESIS Evaluation project) concentrated on students' perspectives and perceptions, as well as their experiences as the main target group and party most affected.

\section{Database}

NOESIS was launched in 2009 to document and evaluate the stepwise implementation of the new middle school in the state of Lower Austria. The underlying purpose was to find out if and how the new middle school fulfilled its goals. The evaluation study was designed as a multi-method, multiperspective and multi-level study, and arranged into four sections: Transitions, School Settings, Instructional Patterns, and Capacity Building (for more details see Katschnig et al., 2019). The "transitions" section included a longitudinal and multi-cohort study to determine which conditions are important for students' successful educational pathways. Three student cohorts were followed from primary school through Secondary I up to the next transition at 9th grade into Secondary II. Along with the conditions for successful school careers, there is also the question of how students perceive their learning support spaces within but also outside the school, and how these perceptions relate to their educational aspirations. For our concept of 
learning support spaces, we take a broader view, not only seeing aspirations as an academic and competitive term so that all students can reach the top, but also that these educational aspirations are embedded in a broader life plan, related to social relationships in their environments, namely family, teachers, peers, school experiences, the expectations of the community and the emotional and social norms evident from the community structure.

Using the data for the first student cohort ( $N=998)$, the following analyses examine whether students' educational aspirations changed over time in the new middle school and if so, how these changes related to the learning support spaces they perceive. Students (and their teachers and parents) from sixteen new middle schools in various villages and towns/cities in Lower Austria were asked to fill in annual questionnaires (paper-pencil) enquiring about their experiences of teaching and learning within and outside school. These sixteen schools were chosen at random from the first generation of schools that decided to implement the new school reform within the administrative structure of the five educational regions in Lower Austria. The questionnaires were administrated by the NOESIS team. A member of the project team conducted the survey directly in class with the students and teachers were asked to leave the classroom.

The following constructs were interrogated annually (see table 1 with example items). The constructs were empirically confirmed (factor analysis, $\left.\mathrm{R}^{2}=53 \%\right)$. The KMO-criteria (.932) and the Bartlett-Test $\left(x^{2}=56437.474\right.$, $d f=3321, p=.00$ ) indicated an interrelationship in the database. Student cultural capital refers to the opportunities students have for engaging in extracurricular activities. In this sense, they were operationalized as cultural activities performed outside the school by the students with their families and/or their friends.

The panel analyses allowed us to document changes in students' educational aspirations and perceived learning support spaces. As discussed earlier, we see the school and the local environment as aspects relating to students' aspirations, as they can be seen as opportunities for or constraints on the formation of specific aspirations and life plans. Aggregated data of the school setting (academic quota, unemployment rate, migrant share) available from the official national statistics (Census Data 2011; Statistics Austria, 2019) were included in the analyses. So local aspects of the schools and their communities could be taken into account. Other concepts relating to locality, local codes and school embeddedness in the wider community could not be used in a survey involving children. For the future, including 
Table 1 Perceived learning support spaces with example items

\begin{tabular}{|c|c|}
\hline Constructs & Example items \\
\hline Educational Aspirations & $\begin{array}{l}\text { How sure are you that you will graduate from school? } \\
\text { I make an effort to get good grades. } \\
\text { What do you want to do after leaving school? }\end{array}$ \\
\hline Maths Self-concept & $\begin{array}{l}\text { Maths is easy for me. } \\
\text { I understand maths quickly. }\end{array}$ \\
\hline German Self-concept & $\begin{array}{l}\text { My German results are good. } \\
\text { I am very good at reading. }\end{array}$ \\
\hline Motivation & $\begin{array}{l}\text { I make an effort to get good grades. } \\
\text { I study even when I don't have to. }\end{array}$ \\
\hline Barriers & $\begin{array}{l}\text { I'm having difficulty with my studies. } \\
\text { If something is difficult, I give up quickly. }\end{array}$ \\
\hline Peer Comparison & $\begin{array}{l}\text { In maths I sit with classmates who can do as much as I can. } \\
\text { In German I work with classmates who can do as much as I can. } \\
\text { I am equally good/better/worse at (subject) than my classmates. }\end{array}$ \\
\hline \multicolumn{2}{|r|}{ learning support spaces } \\
\hline Cooperation & $\begin{array}{l}\text { If I don't know something, my friends help me. } \\
\text { We get along well in class. }\end{array}$ \\
\hline Learning Climate & $\begin{array}{l}\text { I feel comfortable in class. } \\
\text { I definitely want to stay at this school. }\end{array}$ \\
\hline $\begin{array}{l}\text { Teacher-Student } \\
\text { Relationship }\end{array}$ & $\begin{array}{l}\text { The teachers make sure all the students understand everything. } \\
\text { The teachers are also interested in our personal problems and ex- } \\
\text { periences. }\end{array}$ \\
\hline Teacher Aspiration & $\begin{array}{l}\text { ambition, which school/educational pathway student will attend/ } \\
\text { follow afterwards }\end{array}$ \\
\hline Parental Involvement & $\begin{array}{l}\text { I ask my parents to help me with my homework. } \\
\text { I study with my parents. }\end{array}$ \\
\hline Tutoring & $\begin{array}{l}\text { Are you getting tutoring? Which subjects are you getting tutoring } \\
\text { in? } \\
\text { I study with my friends. }\end{array}$ \\
\hline Shared Family Activities & $\begin{array}{l}\text { How do you spend leisure time with your family? Reading, } \\
\text { discussing things, watching television together, eating together, } \\
\text { doing joint sporting activities, housework, gardening, farming, } \\
\text { chatting about everyday life, excursions }\end{array}$ \\
\hline Cultural Capital & $\begin{array}{l}\text { How do you spend your leisure time? Music school, choir, instru- } \\
\text { ments, courses, team sports, youth groups }\end{array}$ \\
\hline Educational Capital & Books at home, parental education \\
\hline
\end{tabular}

these components seem to be a promising strategy to establish the concept of learning support spaces.

Since we hypothesized that schools and their students improve differently, in the first instance we wanted to determine if and how school differences become obvious from students' educational aspirations. 


\section{Results}

The primary aim of the school reform was to offer all students better educational opportunities, to create an environment in which students can develop more ambitious educational aspirations and to encourage as many students as possible into higher education. How students perceive their educational aspirations is an expression of the perceived opportunities that may arise from the reform. Of particular interest is how students perceive the learning support spaces created within the school. The perceived educational aspirations of students at fourteen new middle schools during their four years at school are presented in the descriptive analyses and these indicate the learning support spaces that students perceive within the school. In the following panel analyses, we look at the connection between aspirations and perceived learning support spaces. We want to show how students who felt their aspirations had changed positively over the four years see this in interaction with the perceived spaces.

\section{Descriptive Analyses}

At new middle school, students' educational aspirations increased each year, with more students becoming certain they would achieve their educational aspirations. By 5 th grade $6.25 \%$ intended to complete compulsory schooling at the general level and start an apprenticeship, and this applied to $20 \%$ of 8 th grade students. About $10 \%$ of 8 th grade students thought they would stop at the medium level and go on to an intermediate vocational school offering full-time education from 9th grade with three to four years training that ends in an initial vocational examination. The number of students considering attending the medium level decreased between 5th and 6 th grade and increased in 7 th grade. About $8 \%$ of 7 th grade students intended to finish studying at the general level. These students intended to complete their 9th year of compulsory schooling and then start an apprenticeship. At the beginning of new middle school, about $16 \%$ of students intended to finish the upper level and go to an academic secondary school or a higher vocational school - four to five years of full-time education beginning in the 9th grade and leading to the Matura, the upper school-leaving examination. Over the four years more students said they had high educational aspirations $(31 \%$ in grade $6 ; 42 \%$ in grade 7$)$. More than half of students $(57 \%)$ in 8 th grade intended to go on to the upper level and take the Matura that would enable them to study at university.

The overall mean of students' educational aspirations is high in grade 8 . 


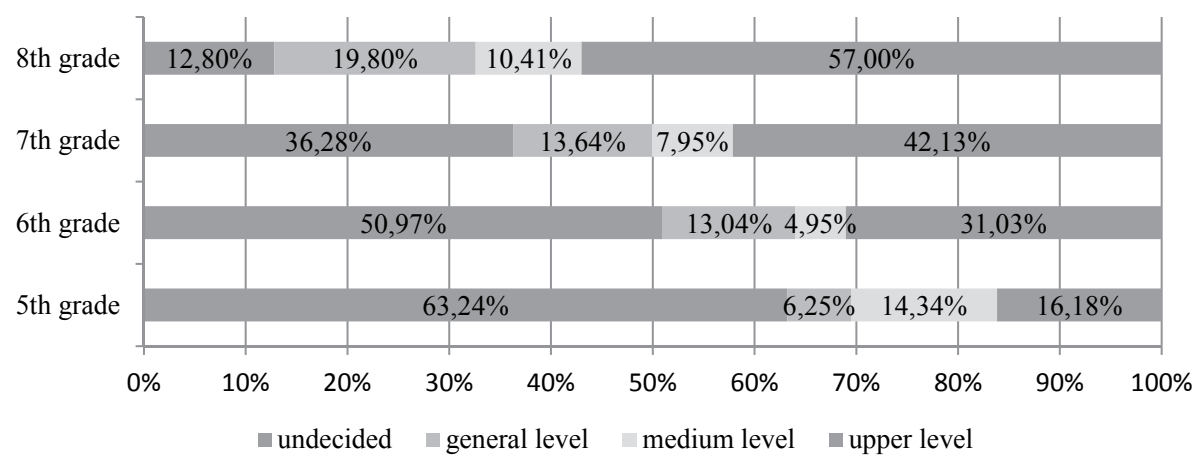

Figure 1: Educational aspirations of new middle school students

Measured on a scale of 1.00 to 3.00 , the student mean value is 2.58 in 5 th and 6th grade. However, many 5th grade students were unsure of their educational aspirations. In 7th grade, students' educational aspirations reached an average of 2.60 and by 8 th grade educational aspirations were even higher at an overall mean of 2.62. If we look at the educational aspirations of students attending new middle school, we can see that the number of students who were undecided about their educational aspirations decreased.

Table 2 School mean values of students' educational aspirations

\begin{tabular}{|c|c|c|c|c|}
\hline & 5th grade & 6 th grade & 7th grade & 8th grade \\
\hline school 1 & 2.60 & 2.55 & 2.73 & 2.73 \\
\hline school 2 & 2.53 & 2.48 & 2.42 & 2.46 \\
\hline school 3 & 2.65 & 2.75 & 2.59 & 2.73 \\
\hline school 4 & 2.62 & 2.50 & 2.54 & 2.47 \\
\hline school 5 & 2.33 & 2.57 & 2.87 & 2.63 \\
\hline school 6 & 2.30 & 2.61 & 2.66 & 2.74 \\
\hline school 9 & 2.86 & 2.67 & 2.79 & 2.75 \\
\hline school 10 & 2.70 & 2.70 & 2.47 & 2.67 \\
\hline school 11 & 2.21 & 2.51 & 2.59 & 2.51 \\
\hline school 12 & 2.59 & 2.75 & 2.67 & 2.55 \\
\hline school 13 & 2.74 & 2.54 & 2.58 & 2.77 \\
\hline school 14 & 2.70 & 2.21 & 2.25 & 2.39 \\
\hline school 15 & 2.68 & 2.56 & 2.68 & 2.72 \\
\hline school 16 & 2.59 & 2.74 & 2.50 & 2.52 \\
\hline overall mean & 2.58 & 2.58 & 2.60 & 2.62 \\
\hline
\end{tabular}


To gain deeper insight, the schools are sorted by students' educational aspiration. Schools differed not only in terms of students' mean levels, but also in how students' educational aspirations changed over the four years. For example, the expectations of 5th grade students at school 2 were lower $\left(\mathrm{MW}^{\text {School } 2}=2.53\right)$ than the overall mean value for all schools $(\mathrm{MW}=2.58)$, but these students did not gain confidence, so by 8 th grade their educational aspirations $\left(\mathrm{MW}^{\text {school } 2}=2.46\right)$ were similar to those of 5 th grade students.

Since it is particularly interesting to see how educational aspirations change, schools were grouped according to different pathways. The starting point was student perceptions in 5th grade. Therefore, we first looked at the mean level of students' educational aspiration in 5th grade. Then we compared the school mean with the overall mean for 5 th grade. Then we looked at how students' educational aspirations changed between the 5th grade and the 8th grade, and compared schools according to change in the mean values. By combining initial perception in 5th grade and change in perceptions in 8th grade, schools with comparable pathways were grouped together. In one group students in three schools had comparatively low educational aspirations in 5th grade, but by 8 th grade these showed an aboveaverage rate of change (see figure 2). In the other two groups, students' perceptions followed a different pathway. In 5th grade, in these two groups student perceptions of educational aspirations were higher. In one group (five schools) these increased slightly by grade 8 . In the other group (six schools) they decreased. Figures 2 to 4 depict the average aspirations of the three schools per group and allow us to trace their trajectory over the four years of schooling.

For example, in this group of schools, students seemed to gain confidence in their learning, and their educational aspirations increased between 5th and 8th grade. In these schools, students' educational aspirations were at a similar level and showed an above-average increase. In this group of schools, perceived student wellbeing was below average in 5th grade, but rose so that by 8 th grade these students were reporting above-average perceptions. Students from schools 5 and 11 described themselves as being particularly motivated compared to others. Additionally, student-teacher relations were good in the two schools and cooperation was strong. At the same time, students were less aware of learning barriers. It should be emphasized that at school 6 cooperation, class climate and well-being were rated higher in the 7th and 8th grades than in previous years and the students thought the school provided guidance in learning. 


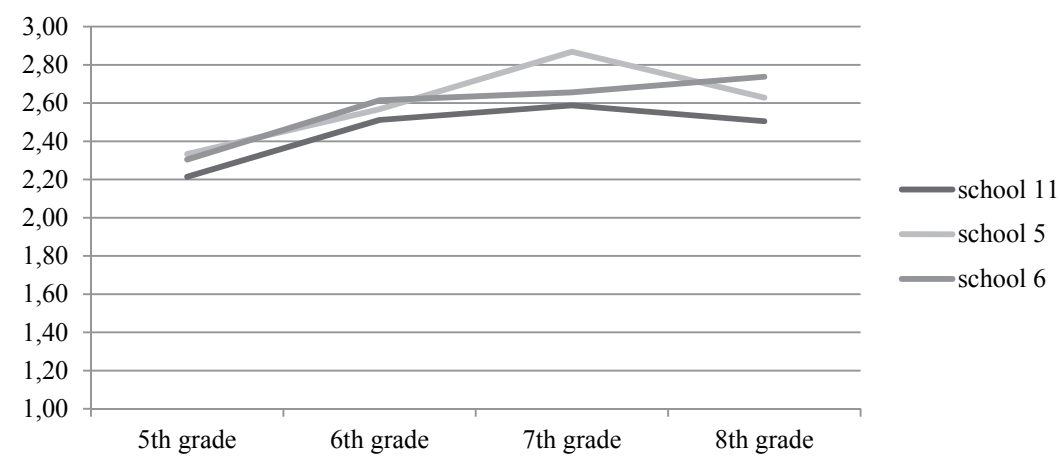

Figure 2: Schools with comparatively low aspirations in 5th grade and above-average increases

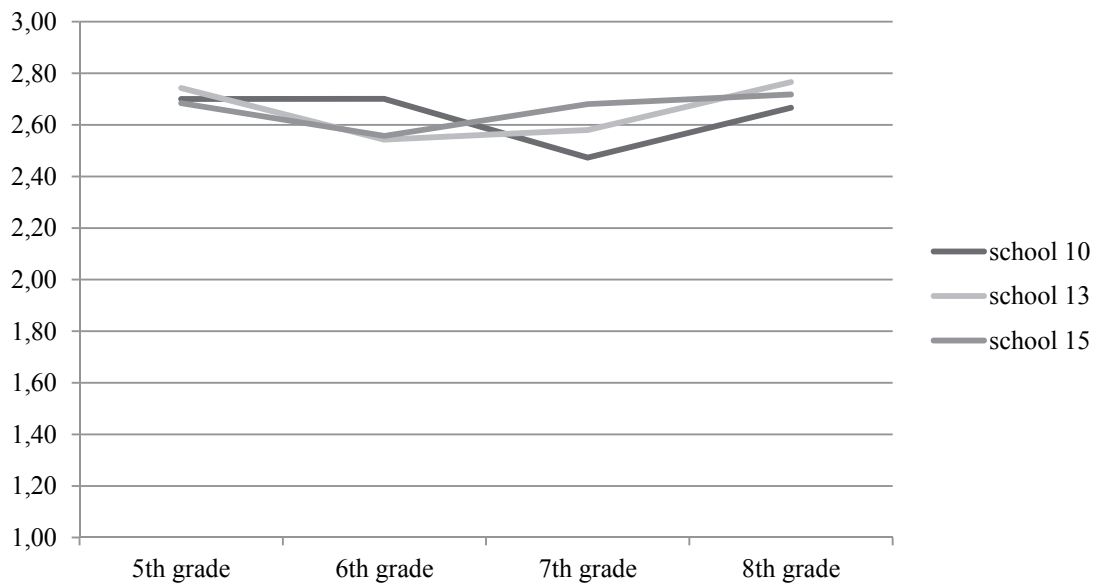

Figure 3: Schools with comparatively high aspirations in 5th grade and little change in aspiration level

There was little difference in the second group of schools between education aspiration levels in 5th grade and 8th grade. In these schools, aspirations in 8 th grade were about the same as in 5 th grade and the change in student aspirations was one of the lowest, with differences between 6 th and 7 th grade only. In these three schools, students' aspirations fluctuated in relation to the overall mean values for learning support spaces over the four years. Students from schools 10 and 13 thought they had above average motivations in the first two years; wellbeing remained at a general level over the four years. In school 13, the teacher-student relations were above average, while cooperation between the students remained average. In 7 th grade the class climate was perceived to be better and there were more learning barriers than in the other years when they rated them average. In contrast, in school 10, students perceptions of class climate in 8th grade were above 


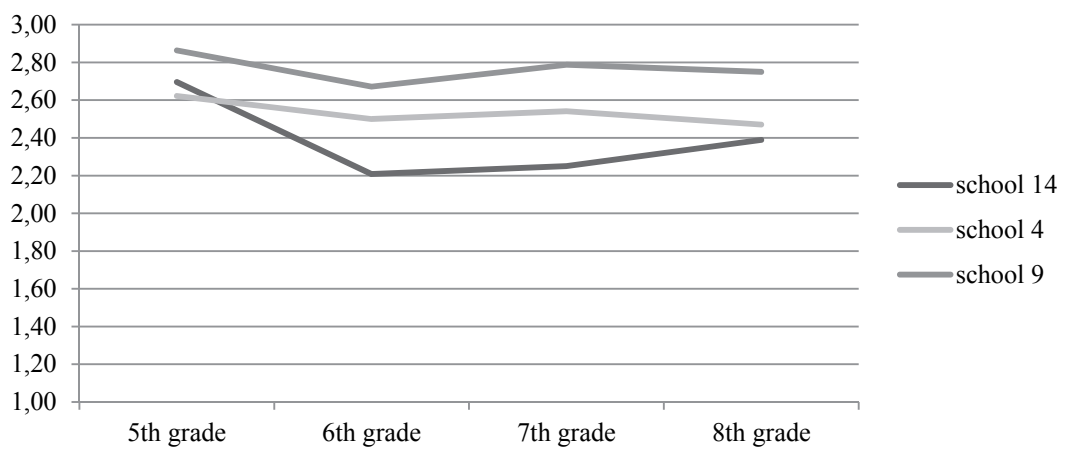

Figure 4: Schools with comparatively high aspirations in 5th grade and lower aspirations in 8 th grade

average and relations with teachers were above average in 5 th grade, but then fell to average. However, there were more learning barriers. Relations with teachers in school 15 were considered poor in 8th grade and were below average. In previous years, relations and learning barriers had been average. However, learning barriers were perceived as being low in 8th grade. The class climate in this school was also below average in 7 th and 8 th grade.

In comparison, there were three schools where students' educational aspirations in 5th grade were as high as those in schools in the previous group, but in these schools students' educational aspirations were lower in 8 th grade than they had been in 5 th grade. Educational aspirations at these schools fell below average. In schools 4 and 14 students' perceptions hardly changed. In school 4, students' perceptions of learning support spaces over four years was close to the overall mean. This also applied to perceptions of class climate, cooperation, well-being, learning barriers and achievement goal orientations. Students' learning motivation was above average in 5th grade, but remained average thereafter. The teacher-student relationship developed positively after fifth grade and then remained average. At school 14 , students' perceptions differed from those of students at other schools. During their entire time at the school, well-being, motivation, teacher-student relationship, class climate and cooperation were below average. They also expressed a lower learning goal orientation than students from other schools. At school 9, perceived well-being remained slightly above average until 8th grade when it increased. In contrast, perceived motivation remained below average from 6 th grade onwards. Students in the 5 th and 8th thought cooperation with classmates and class climate was better than in other grades, when they were below average, but in those years students reported fewer learning barriers. 
These descriptive findings indicate that schools differ in how students' perceptions shape learning support spaces and it also shows students think schools offer opportunities to change students' educational aspirations. The reason students in one group of schools reported a positive change in perceived educational aspirations may be that over the four years students were highly motivated, had above-average perceptions of class climate, a good relationship with teachers and the school promoted a learning goal orientation. Schools in the other groups were only partially able to make these opportunities available as can be seen in the fact that students' perceptions of the various learning support spaces either decreased or remained unchanged over the four years. The descriptive results showed that 8 th grade students reported high educational aspirations and that educational aspirations differed between schools over the course of four years. Students' perceptions of learning spaces also changed and the descriptive results show that schools made different opportunities available to students. It would be interesting to determine how students' educational aspirations changed in relation to how the learning support spaces offered by schools shape their perceptions and if these factors affected their educational aspirations.

\section{Panel Analyses}

A panel analysis enables us to see the effect of various factors on educational aspirations, to determine whether and to what extent school site matters and which influences can be attributed to changes in learning support spaces in schools and outside schools. To answer these questions, fixed effect models (Rabe-Hesketh \& Skorndal, 2012) were applied $(\mathrm{N}=998)$. The base model of the longitudinal analysis shows that there are significant differences between schools in changes in students' educational aspirations. These are examined individually to enable a more precise analysis of the aspects of learning support spaces in schools and family spaces behind this.

We understand learning support spaces to include both in-school and out-of-school student experiences:

If only aspects of school space (model inner school space: $\mathrm{ICC}=5.9 \% ; \mathrm{R}^{2}=$ $15.2 \%)$ are considered, verbal self-concept and cooperation in class are especially important. Students who had support from their classmates over the four years had higher educational aspirations. Students who have learning content explained to them when they do not understand something or who support their classmates have stronger aspirations. Improvements in verbal self-concept and in mathematical self-concept over the four years promoted 
Table 3 Panel analysis of students' educational aspirations (*sig. $<.05,{ }^{* *}$ sig. $<.01,{ }^{* * *}$ sig. $\left.=.000\right)$

\begin{tabular}{|c|c|c|c|c|c|}
\hline $\begin{array}{l}\text { Students' educa- } \\
\text { tional aspirations }\end{array}$ & Base model & $\begin{array}{l}\text { Model inner } \\
\text { school space }\end{array}$ & $\begin{array}{c}\text { Model family } \\
\text { space }\end{array}$ & $\begin{array}{l}\text { Combined } \\
\text { model }\end{array}$ & $\begin{array}{l}\text { Model within } \\
\text { school spaces }\end{array}$ \\
\hline Intercept & $1.295(.058)^{* * *}$ & $1.903(.231)^{* * *}$ & $0.833(.116)^{* * *}$ & $0.062(.312)$ & $-0.180(.408)$ \\
\hline self-concept maths & & $0.091(.036)^{*}$ & & $0.093(.046)^{*}$ & $0.036(.058)$ \\
\hline verbal self-concept & & $0.275(.048)^{* * *}$ & & $0.151(.059)^{* *}$ & $0.156(.075)^{*}$ \\
\hline motivation & & $0.224(.058)^{* * *}$ & & $0.312(.072)^{* * *}$ & $0.282(.095)^{* *}$ \\
\hline barriers & & $-0.083(.042)^{*}$ & & $-0.027(0.055)$ & $-0.028(.081)$ \\
\hline peer comparison & & $0.058(.050)$ & & $0.194(.063)^{* *}$ & $0.222(.081)^{* *}$ \\
\hline cooperation & & $0.280(.062)^{* * *}$ & & $-0.088(.082)$ & $0.018(.105)$ \\
\hline learning climate & & $-0.983(.052)^{* * *}$ & & $-0.229(.076)^{* *}$ & $-0.128(.098)$ \\
\hline $\begin{array}{l}\text { teacher student } \\
\text { relationship }\end{array}$ & & $-0.053(.060)$ & & $-0.056(.080)$ & $-0.216(.011)^{*}$ \\
\hline $\begin{array}{l}\text { parental } \\
\text { involvement }\end{array}$ & & & $0.001(.000)^{* * *}$ & $.0004(.000)^{* * *}$ & $.0004(.000)^{* * *}$ \\
\hline $\begin{array}{l}\text { out of school } \\
\text { tutoring }\end{array}$ & & & $-0.068(.040)$ & $0.010(.045)$ & $-0.017(.017)$ \\
\hline $\begin{array}{l}\text { shared family } \\
\text { activities }\end{array}$ & & & $0.050(.045)$ & $0.007(.050)$ & $-0.041(.064)$ \\
\hline cultural capital & & & $0.243(.046)^{* * *}$ & $0.206(.050)^{* * *}$ & $0.253(.063)^{* * *}$ \\
\hline educational capital & & & $0.088(.015)^{* * *}$ & $0.054(.016)^{* *}$ & $0.074(.021)^{* * *}$ \\
\hline $\begin{array}{l}\text { language spoken at } \\
\text { home }\end{array}$ & & & $-0.065(.029)^{*}$ & $-0.056(.031)$ & $0.004(.039)$ \\
\hline gender & & & $0.030(.040)$ & $0.075(.045)$ & $0.090(.056)$ \\
\hline teacher aspiration & & & & $0.039(.013)^{* *}$ & $0.031(.017)$ \\
\hline academic quota & & & & & $0.006(.023)$ \\
\hline unemployment rate & & & & & $0.004(.050)$ \\
\hline migrant share & & & & & $0.014(.014)$ \\
\hline variance intercept & $0.049(.020)$ & $0.043(.017)$ & $0.019(.010)$ & $0.008(.007)$ & $0.005(.006)$ \\
\hline variance residual & $0.815(.023)$ & $0.690(.020)$ & $0.561(.020)$ & $0.535(.312)$ & $0.495(.026)$ \\
\hline
\end{tabular}


change in students' educational aspirations. Verbal self-concept seems to be especially important. Change in learning motivation plays an essential role in changing aspirations. Students whose learning motivation increased over the four years enjoyed solving school tasks, which also strengthened educational aspirations. The effect of learning climate in class is striking. Students who think the learning climate is steadily improving also report an increase in aspirations. The model shows clear differences between schools. We can therefore summarize that learning support spaces within schools can foster students' aspirations and that this differs across schools. Cultural capital is particularly important in relation to family space (family model: ICC $=3.3 \%$; $\left.\mathrm{R}^{2}=32.9 \%\right)$ and engendering aspirations. Family attitude and joint participation in cultural activities have a positive effect on aspirations. In contrast, spending more time together doing different activities may enhance interactions within the family, but does not necessarily develop students' aspirations. Learning support from the family was shown to have less of an effect in promoting aspirations. Similarly, private tutoring did not systematically encourage aspiration formation. The analysis also shows that parental involvement has a positive effect on aspirations, but only to a small extent. In this model, male/female differences in the formation of aspirations was investigated, as was the family's linguistic background. The results show there was no difference between girls and boys on either of these. It is noteworthy, however, that aspirations fell among students from German-speaking families but not among and classmates from bilingual or multilingual families. The analysis also shows that students' educational aspirations differed between schools. If we combine both models (combined model: $\mathrm{ICC}=1.5 \%$; $\mathrm{R}^{2}=37.2 \%$ ), selfconcept, learning motivation, class climate and family cultural capital are most interesting. Changes are evident in cooperation and peer comparisons in class. In the combined model, where cooperation among students is observed, there is no systematic difference as there is in the peer comparisons. In both this model and the single model there does not seem to be any difference in boys' versus girls' aspirations. Mathematical self-concept, however, does have a small positive impact on students' educational aspirations. The same can be observed in student-teacher relationship and family educational status. Nevertheless, it must be noted that in this model the differences between students' educational aspirations are not significant. This is also reflected in the last model (school environment model: $\mathrm{ICC}=1 \% ; \mathrm{R}^{2}=42.1 \%$ ) which takes the socio-cultural aspects of the school environment into account. None of the three aspects (academic quota, unemployment rate, migrant share) is systematically linked to student aspirations. Positive change in educational aspirations is of course linked to factors of the learning support space within the school and depends on family aspects. 


\section{Discussion}

The results indicate that by creating a supportive school space in the form of a unique school culture, schools can establish the socio-spatial conditions necessary for developing practices that enable students to develop a sense of school belonging (Cudworth, 2015), which may be an important parameter associated with educational aspirations and future plans. This can be interpreted as a positive message for schools and regarding the potential benefits of offering supportive spaces for students. The relatively weak relevance of internal school space variables could be down to the different ways in which schools adapted the reforms, which policy initiators may find disappointing. Nevertheless, new middle schools did not create learning support spaces because of the reform but in spite of it. This indicates that in the first instance schools have to adapt the innovations and then translate them in such a way as to accommodate the local knowledge and culture and thereby ensure that students are guaranteed supportive spaces. These aspects appear to be of relevance for future educational policies as the study emphasizes that schools approach the same policies differently, and this in turn affects students' perceptions of support from their schools and families. Comprehensive policies often see schools as fixed and linear entities, which often lead to simplified solutions and do not address the problem fully as they neglect interactions between space and actors. Education and classroom learning are therefore characterized as emergent, but the locality is overlooked. Acknowledging this in educational policy research may help us understand why schools act differently.

The limitations of our study are related to the well-known problem of differentiating between neighbourhood effects and school effects. The difficulty lies in how we can measure, model and attribute variance at different levels in the analyses, and is often mentioned in relation to studies focusing on the influence of neighbourhood effects on students' academic achievement and students' success (see e.g. Horr, 2016). This is also reflected in our data so we must assume that effects at the school or neighbourhood level may also be the result of effects at another level.

It is often claimed that the promotion of educational aspirations is strongly focused on middle-class aspirations and not on what the students themselves see as desirable aims (Holloway \& Pimlott-Wilson, 2011). As the conception of learning supportive spaces in this article includes the opportunities for achieving individual goals with help from the school and through outside activities and relationships, it may help if we extend this one-sided 
view and understand educational aspirations as being not merely the product of the individual's choices but as being embedded in a broader complex of locally constituted processes and knowledge. This article provides a first impression of the information such an approach is capable of giving within the scope of comprehensive school reforms. Further research might bear this in mind and focus more strongly on the underlying local knowledge and expectations held by the school community regarding student development and educational aspirations. Mixed-methods studies could investigate the interconnections between school culture, school reform policy and the local community. A mixed method approach would enable the researcher to collect the views of other members of the school community (teachers, school leaders, parents, community representatives), so that concepts of locality, local codes, embeddedness of schools within a broader community, as a locally underpinning social structure can be better dealt with. In the current survey involving children, it was not possible to incorporate all these concepts into the empirical data.

On the one hand, the new middle school reform was intended to expand students' educational goals, while, on the other hand, policy makers expected each school to achieve this individually through educational measures (team teaching, teaching formats etc.) in order to create individual learning support spaces. We therefore looked at the fact that schools differ in how students achieve their aspirations and how schools differ in learning support spaces. Schools manage to do this in different ways, but learning support spaces are important to all and may extend social and educational geography.

\section{Acknowledgements}

The NOESIS evaluation study received government funding from the Federal State of Lower Austria from 2009 to 2017. Supported by funds from the Oesterreichische Nationalbank (Austrian Central Bank, Anniversary Fund, project number: 17706), a follow-up-study followed the three student cohorts in a longitudinal transition study which asked the students about their retrospective school experiences in Secondary II. We would like to thank the two anonymous reviewers for their comments and Silvie R. Kučerová for the possibility to contribute to this volume. Additionally we would like to thank Sylvia Petter for proofreading the manuscript. 


\section{References}

Ball, S. J. (2006). Education policy and social class: The selected works of Stephen J. Ball. London, UK: Routledge.

Braun, A., Ball, S. J., Maguire, M., \& Hoskins, K. (2011). Taking context seriously: Towards explaining policy enactments in the secondary school. Discourse: Studies in the Cultural Politics of Education, 32(4), 585-596.

Brown, G. (2011). Emotional geographies of young people's aspirations for adult life. Children's Geographies, 9(1), 7-22.

Buendia, E., Ares, N., Juarez, B. G., \& Peercy, M. (2004). The geographies of difference: The production of the east side, west side, and central city school. American Educational Research Journal, 41(4), 833-863.

Collins, D., \& Coleman, T. (2008). Social geographies of education: Looking within, and beyond, school boundaries. Geography Compass, 2(1), 281-299.

Cudworth, D. (2015). Schooling, space and social justice. Power \& Education, 7(1), 73-89.

Drope, T., \& Jurczok, A. (2013). Weder gleichwertig noch gleichartig. Besonderheiten und Problemlagen Integrierter Sekundarschulen in einem sozio-ökonomisch schwachen Stadtteil Berlins. Zeitschrift für Pädagogik, 59(4), 496-507.

Eirmbter, W. H. (1982). Bildungsaspirationen und sozialökologische Kontext. In L. A. Vaskovics (Ed.), Umweltbedingungen familialer Sozialisation (p. 237-254). Stuttgart: Enke.

Fink, D. (2000). Good schools/real schools. Why school reform doesn't last. New York, USA: Teachers College Press.

Freytag, T., \& Jahnke, H. (2015). Perspektiven für eine konzeptionelle Orientierung der Bildungsgeographie. Geographica Helvetica, 70, 75-88.

Freytag, T., Jahnke, H., \& Kramer, C. (2015). Geographische Bildungsforschung. DDS - Die deutsche Schule, 107(1), 79-95.

Gulson, K. N. (2008). Urban accomodations: Policy, education and a politics of place. Journal of Educational Policy, 23(2), 153-163.

Gulson, K. N., \& Symes, C. (2007). Knowing one's place: space, theory, education. Critical Studies in Education, 48(1), 97-110.

Gustafson, K. (2011). No-go- area, no-go- school: Community discourses, local school market and childrens's identity work. Children's Geographies, 9(2), 185-203.

Hanson Thiem, C. (2009). Thinking through education: The geographies of contemporary educational restructuring. Progress in Human Geography, 33(2), 154-173.

Hargreaves, A. (2002). Sustainability of educational change: The role of social geographies. Journal of Educational Change, 3, 189-214.

Holloway, S. L., Brown, G., \& Pimlott-Wilson. H. (2011). Editorial introduction: Geographies of education and aspiration. Children's Geographies, 9(1), 1-5.

Holloway, S. L., Hubbard, P., Jöns, H., \& Pimlott-Wilson, H. (2010). Geographies of education and the significance of children, youth and families. Progress in Human Geography, 34(5), 583-600.

Holloway, S. L. \&, Pimlott-Wilson, H. (2011). The politics of aspiration: Neo-liberal education policy, 'low' parental aspirations, and primary school Extended Services in disadvantaged communities. Children's Geographies, 9(1), 79-94. 
Holloway, S. L., \& Jöns, H. (2012). Geographies of education and learning. Transactions of the Institute of British Geographers, 37(4), 482-488.

Horr, A. (2016). Nachbarschaftseffekte. In C. Diehl et al. (Eds.), Ethnische Ungleichheiten im Bildungsverlauf (pp. 398-430). Wiesbaden, Germany: Springer.

Knapp, M., \& Kilian, M. (2019). School culture matters! Schulkulturelle Komponenten im Kontext der NMS-Reform. Erziehung \& Unterricht, 169(5-6), 520-528.

Kustatscher, M. (2017). The emotional geographies of belonging: Children's intersectional identities in primary school. Children's Geographies, 15(1), 65-79.

Löw, M. (2001). Raumsoziologie. Frankfurt am Main: Suhrkamp.

Midtsundstad, J. H., \& Langfeldt, G. (2018). The school programme: A key link between contextual influence and school development. Scandinavian Journal of Educational Research, 64(1), 87-97.

Manchester, H., \& Bragg, S. (2013). School, ethos and the spatial turn: "Capacious" approaches to research and practice. Qualitative Inquiry, 19(10), 818-827.

Rabe-Hesketh, S., \& Skorndal, A. (2012). Multilevel and longitudinal modeling using stata. volume I: Continuous responses. College Station, Texas: Stata Press.

Statistics Austria (2019). Education: https://www.statistik.at/web_en/statistics/ PeopleSociety/education/index.html [13.01.2020].

Strohmaier, B., \& Immerfall, S. (2016). Die Gemeinschaftsschule im Sozialraum: Quantitative Analyse sozialökologischer Erfolgsfaktoren. In T. Bohl, \& A. Wacker (Eds.), Die Einführung der Gemeinschaftsschule in Baden-Württemberg. Abschlussbericht der wissenschaftlichen Begleitforschung (WissGem) (pp.73-92), Münster, Germany: Waxmann.

Taylor, C. (2009). Towards a geography of education. Oxford Review of Education, 35(5), 651-669.

Tyack, D. \&, Tobin, W. (1994). The "grammar" of schooling: Why has it been so hard to change? American Educational Research Journal, 31(3), 453-479.

Werlen, B., \& Reutlinger, C. (2019). Sozialgeographie. Eine disziplinäre Positionierung zum Sozialraum. In F. Kessl, \& C., Reutlinger (Eds.), Handbuch Sozialraum. Sozialraumforschung und Sozialraumarbeit (pp. 23-44). Wiesbaden, Germany: Springer.

Yoon, E.-S. (2016). Young people's cartographies of school choice: The urban imaginary and moral panic. Children's Geographies, 14(1), 101-114.

Zangger, C. (2015). The social geography of education: Neighborhood, class composition, and the educational achievement of elementary school students in Zurich, Switzerland. Zeitschrift für Soziologie, 44(4), 292-310.

\section{Authors:}

Mariella Knapp

University of Vienna

Department of Education

Section School, Education and Society

Vienna

1090

Austria

E-mail: mariella.knapp@univie.ac.at 
Michaela Kilian

University of Vienna

Department of Education

Section School, Education and Society

Vienna

1090

Austria

E-mail: michaela.kilian@univie.ac.at

Tamara Katschnig

University College of Teacher Education Vienna/Krems (KPH)

Vienna

1180

Austria

E-mail: tamara.katschnig@kphvie.ac.at 